\title{
Analysis of the stability of the outer partition of a steel frame house using FEM
}

\author{
Mariusz Kosiń ${ }^{1, *}$ and Maciej Major ${ }^{1}$ \\ ${ }^{1}$ Czestochowa University of Technology, Faculty of Civil Engineering, Akademicka Street 3, 42-200 \\ Częstochowa, Poland
}

\begin{abstract}
The subject of the analysis is a separate fragment of the external partition located in the ground floor of a residential building made in the technology of light steel skeleton without stiffening plating. The motivation to carry out this analysis is, among others Investors' growing interest in alternative solutions to traditional single-family housing. The selection of the considered fragment was made on the basis of maximum displacements obtained as a result of numerical analysis carried out in Robot Structural. Then, for the selected structural element of the wall, three calculation models in the Ansys program for the assessment of bending - torsional analysis were made. The calculation models adopted for the calculations differed in the way in which the bracing used were assembled. One of them included the author's own development of an insert stiffening the transverse profile at the bracing assembly site. The results of the calculations showed the legitimacy of strengthening the structure when the stiffening plating is removed.
\end{abstract}

\section{Introduction}

The technology of light steel skeleton based on thin-walled elements in industrial and single-family construction as well as the superstructure of existing buildings is used. Thinwalled elements are characterized by the fact that one of the dimensions determining the cross-section (thickness) is incomparably small in relation to the others [1,2]. In the design of structures made of thin-walled elements, the application of the basic hypotheses applicable to solid steel elements does not apply.

Investors are increasingly looking for optimal technological solutions. One of such solutions is construction in the lightweight frame construction technology. Thanks to the lightweight construction, quick realization, easy rebuilding, the use of recycling materials and meeting the requirements of building physics houses in light steel construction can easily compete with those built in other, e.g. traditional technologies [3]. The use of modern technologies based on thin-wall structures substantially reduces the time to complete the investment (construction of a building). For testing the structure in this technology FEM analysis is commonly used by researches [4]. The numerical modelling of thin-walled construction were conducted in [5-8].

\footnotetext{
*Corresponding author: mariusz.kosin@pcz.pl
} 
Numerical analysis of a fragment of the skeleton of an external wall structure made of thin-walled C-profiles is presented in the article. The selection of the fragment in question was made on the basis of the maximum displacements obtained as a result of numerical analysis carried out at Robot Structural. Three calculation models: a building model with all sheathing, a building model without stiffening sheathing in the ground floor part and a building model without stiffening sheathing in the ground floor part but reinforced with vertical wall bracing are included in this analysis. More on the model itself and the analysis carried out is described in the article [9]. Three computational models were prepared for the selected bending-torsional analysis for the selected wall element. These calculations were made in the Ansys Academic Research program based on Finite Element Method. Calculation models adopted for calculations differed in the way of bracing fixing, and one of them took into account the author's development of the stiffening insert [10]. The carried out calculations showed the legitimacy of using bracing when the stiffening sheathing was removed and additional reinforcement at the point of connection with the profile.

\section{FEM model}

Model of external wall structure without stiffening plating subjected to bending - torsional analysis is shown in Fig. 1. The selection of the considered fragment was made on the basis of maximum displacements obtained from the analysis of the stability of the building body [9]. The analyzed building was based on thin-walled C140 profiles spaced modularly every $60 \mathrm{~cm}$. The values of read nodal displacements in the selected fragment of the structure were used as boundary conditions in the detailed analysis conducted in the Ansys Academic Research program.

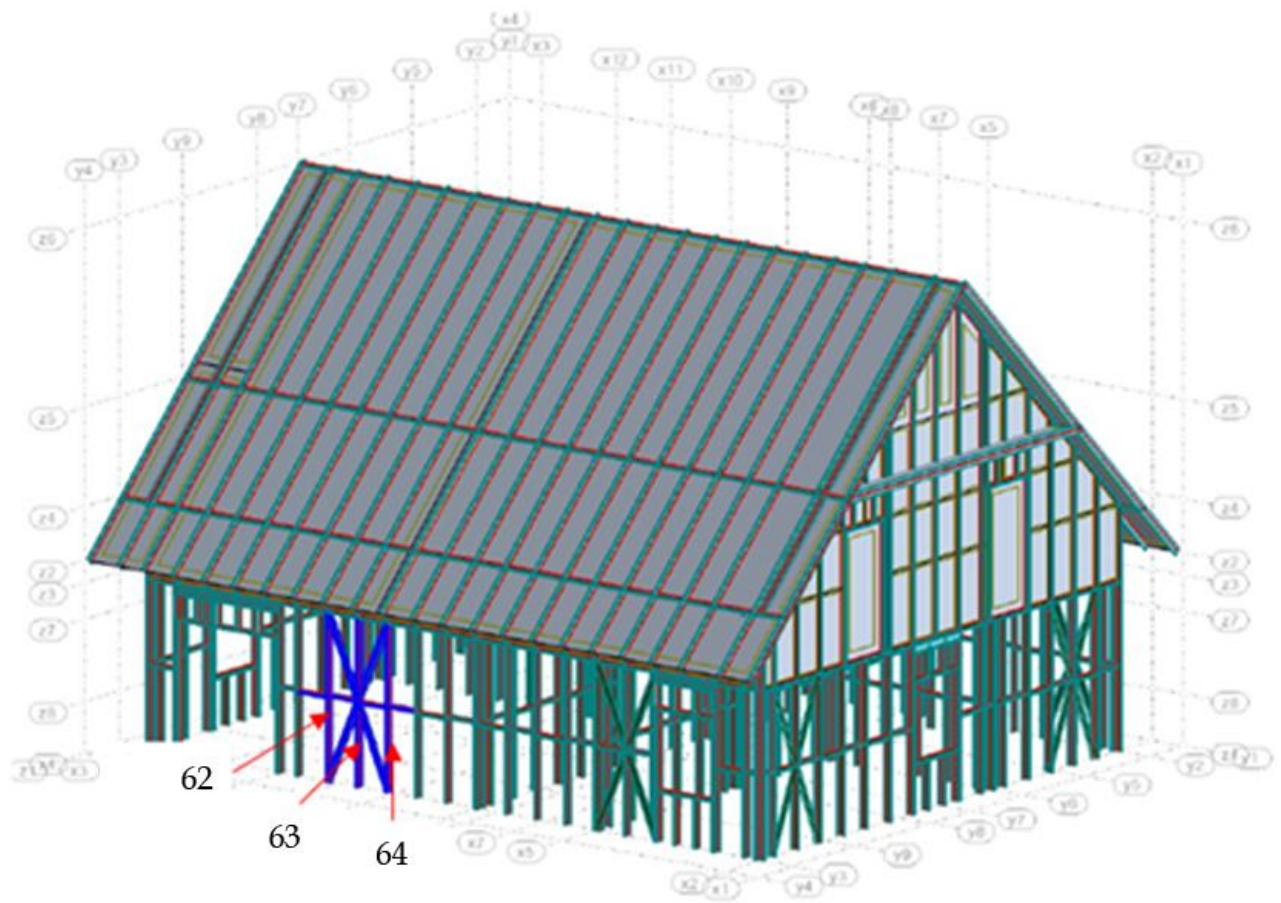

Fig. 1. Calculation model of the single-family house structure in Autodesk Robot Structural with selected profiles for detailed analysis [9]. 
The detailed analysis included three computational models which were deprived of stiffening plating in the ground floor. Model 1 was treated as the initial one without plating (Fig. 2b), Model 2 with vertical bracing (Fig. 2c) and Model 3 with bracing additionally reinforced with mounting inserts at the bracing connections with the column (Fig. 2d). The stiffening elements were made in 3D printing technology using ABS filament [10]. The height of the stiffener $(140 \mathrm{~mm})$ corresponded to the cross section of the C140 thin-walled profile from which the wall model was built.

a)

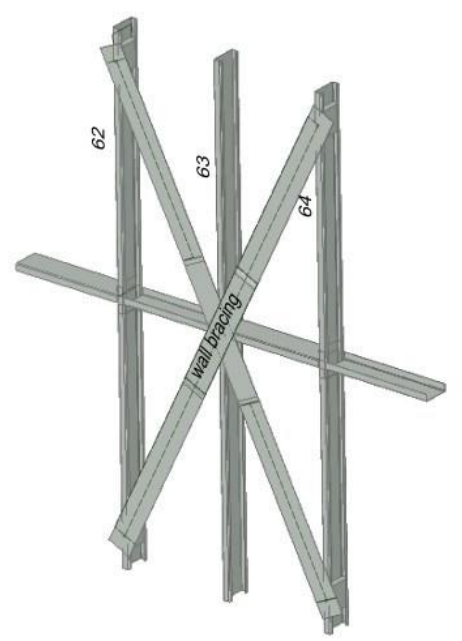

c)

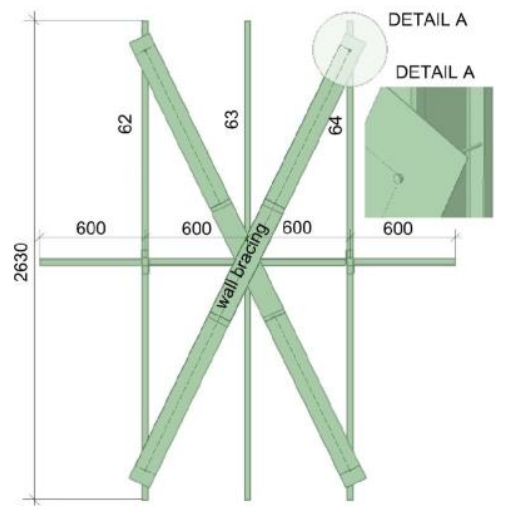

b)

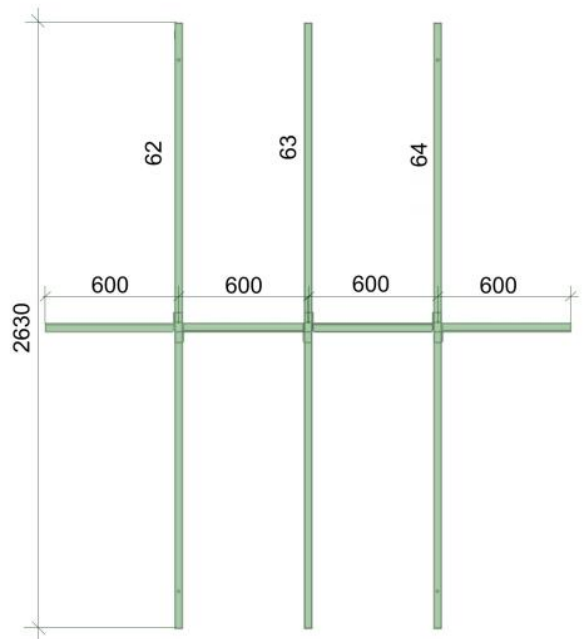

d)

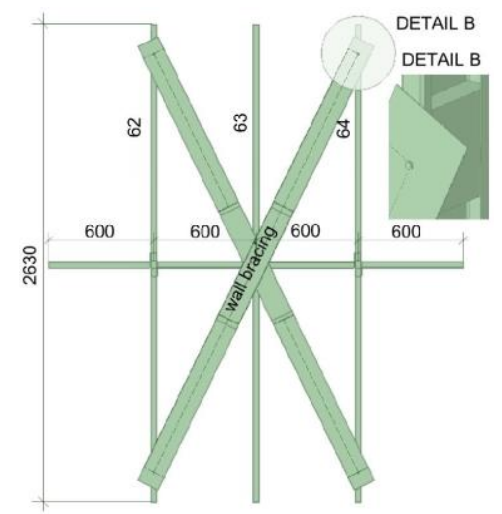

Fig. 2. Diagram of the analyzed fragment of the wall: a) general view of selected profiles, b) Model 1 without stiffening, c) Model 2 with bracing attached without stiffening (detail A), d) Model 3 with bracing attached with stiffening (detail B).

Mapping of boundary conditions in Ansys was possible due to assigning displacements read from Robot Structural program applied in the center of gravity of C140 cross section (Fig. 3a). Fixing supports were adopted in places where the partition is connected with the foundation using M10 anchor rods (Fig. 3b).

In the adopted model, Shell181 shell elements for thin-walled elements and Solid187 solid elements for screws were generated. In surface objects, a 4-node element with 6 degrees of freedom at each node was used, while solid elements were defined as a 10-node element with 3 degrees of freedom at each node. Two types of contact were adopted for modeling contacts between parts. Bonded contact, which means that a pair of contacts cannot separate and move, and a Frictional contact that allows contacts to separate and move each other [11-14]. 
a)

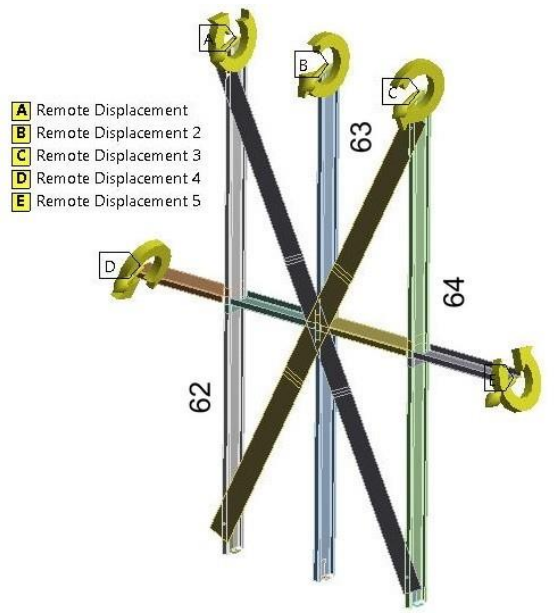

b)

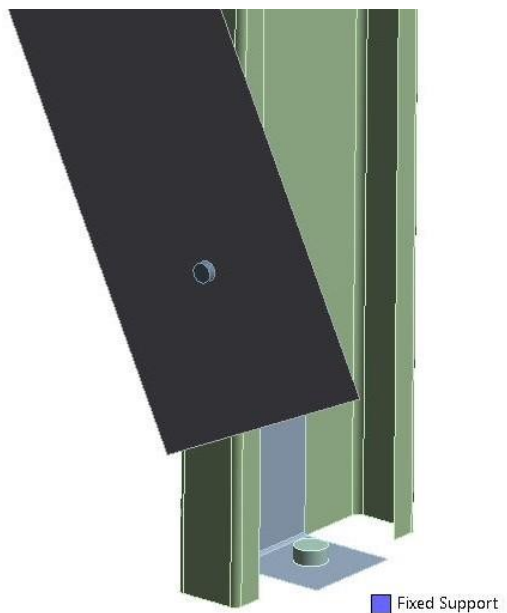

Fig. 3. Boundary conditions of the analyzed fragment: a) displacements applied in the center of gravity of the cross-section of the profiles, b) support in the form of M10 anchor (an example of the connection of bracing with a long screw).

Depending on the considered model, the generated finite element mesh differed in the number of nodes and elements (Table 1).

Table 1. Finite element statistics.

\begin{tabular}{|c|c|c|}
\hline Model & $\begin{array}{c}\text { Number } \\
\text { of nodes }\end{array}$ & $\begin{array}{c}\text { Number } \\
\text { of elements }\end{array}$ \\
\hline Model 1 & 168355 & 164379 \\
\hline Model 2 & 232535 & 221360 \\
\hline Model 3 & 521576 & 418642 \\
\hline
\end{tabular}

\section{Analysis of results}

In the considered models torsion angles along the length of the flange in the plane of joining the bracing for selected columns with numbers 62,63 and 64 were read. Figs. $4 \div 6$ show the torsion angle distribution in selected elements. The results of the analysis show the effect of bracing as well as the method of their fixings on increasing torsional stiffness. The minimum torsion angle occurs in the wall with stiffening elements (Model 3). For example, for the middle column of the analyzed partition, the difference between Model 1 and Model 3 in the torsion angles read at the joining height, it is $3 \%$ at the bottom of the column and $40 \%$ at the top of the column, respectively. 


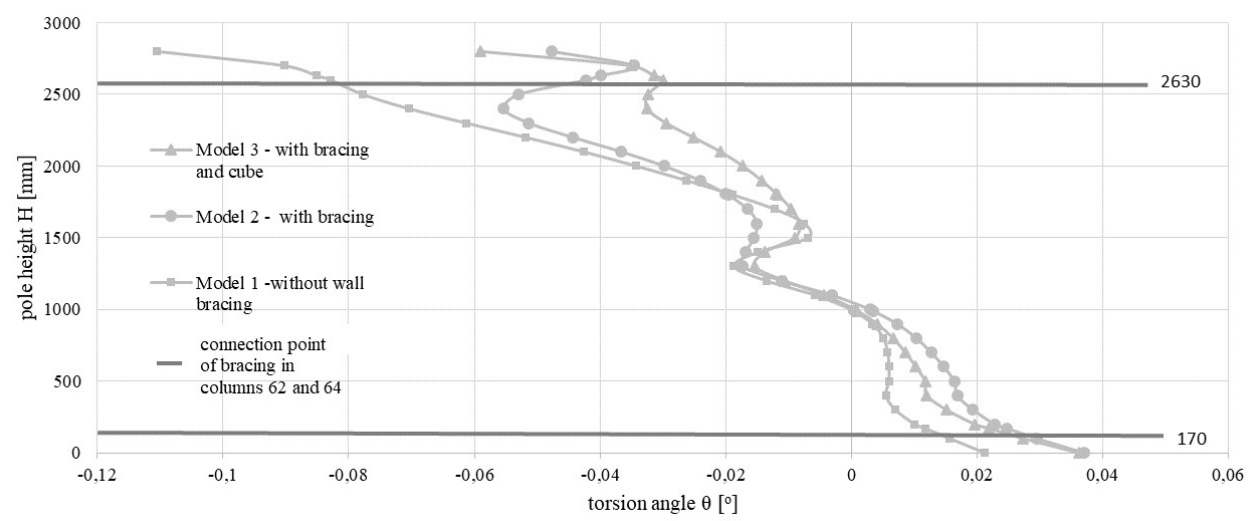

Fig. 4. The course of torsion angle variability for the column no. 62 in the bracing attachment plane.

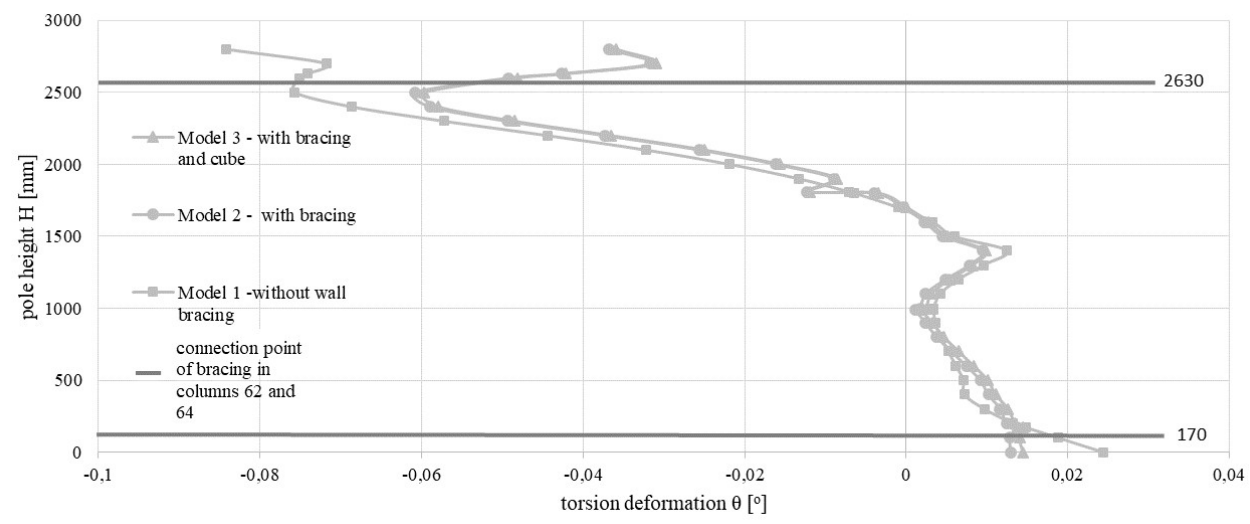

Fig. 5. The course of torsion angle variability for the column no. 63 in the bracing attachment plane.

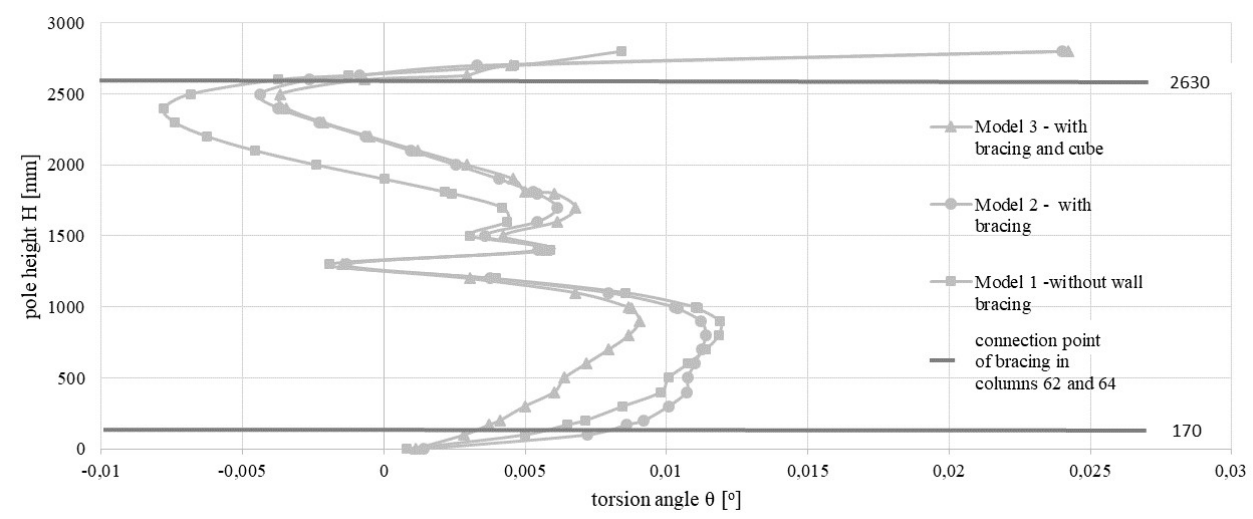

Fig. 6. The course of torsion angle variability for the column no. 64 in the bracing attachment plane.

Table 2 summarizes the average value of the torsion angle for individual models and analyzed columns. An increase in torsional stiffness due to the use of the mounting insert is noticeable in all models and analyzed columns. For example, the difference between the torsion angle for Model 3 is about 22\% smaller than for Model 2. 
Table 2. Average values of the torsion angle along the entire length in the bracing attachment plane.

\begin{tabular}{|l|c|c|c|}
\cline { 2 - 4 } \multicolumn{1}{c|}{} & $\begin{array}{c}\text { Model 1 } \\
\text { - no wall } \\
\text { bracing } \\
\theta\left[^{\circ}\right]\end{array}$ & $\begin{array}{c}\text { Model 2 } \\
\text { - with bracing } \\
\theta\left[^{\circ}\right]\end{array}$ & $\begin{array}{c}\text { Model 3 } \\
\text { - with bracing } \\
\text { and stiffening } \\
\theta\left[^{\circ}\right]\end{array}$ \\
\hline COLUMN 1 & 0.023 & 0.011 & 0.007 \\
\hline COLUMN 2 & 0.014 & 0.009 & 0.008 \\
\hline COLUMN 3 & 0.007 & 0.007 & 0.006 \\
\hline
\end{tabular}

\section{Conclusions}

The construction model of a multi-story building without stiffening plating in the ground floor part loses overall stability, which was presented in [9]. On the other hand, the numerical analysis of the separated part of the wall allowed to assess the impact of the bracing used and the method of its fixing on bending - torsional displacements. The results of the analysis show a reduction in the torsion angle and thus an increase in torsional stiffness. Calculations based on the finite element method can be useful in scientific research and engineering practice.

\section{References}

1. S. Piechnik, Thin-walled bars - open (Pręty cienkościenne - otwarte) (Wydaw. Politechniki Krakowskiej im. Tadeusza Kościuszki, Kraków, 2000, in polish)

2. Szychowski A. Thin-Wall. Struct. 76, 42-55 (2014)

3. O. Umnova, D. Tuev, T. Giyasov, MATEC Web Conf. 193, 03037 (2018)

4. E. Kormaníková, K. Kotrasová, Appl. Mech. Mater. 617, 247-250 (2014)

5. J. Flodr, M. Krejsa, D. Mikolasek, O. Sucharda, L. Zidek, Appl. Mech. Mater. 617, 171-174 (2014)

6. I. Balazs, J. Melcher, Transactions of the VSB - Technical University of Ostrava, Civil Engineering Series, 13, 2, 1-12 (2013)

7. P. Różyło, P. Wysmulski, K. Falkowicz, Int. J. of Applied Mechanics and Engineering, 22, 2, 393-402 (2017)

8. A. Floricel, G. Zagari, V. Unggureanu, Bulletin of the Transilvania University of Braşov CIBv, 8, 57, Special Issue No. 1-2015 (2015)

9. M. Kosiń, Zeszyty Naukowe Politechniki Częstochowskiej, 25, $92-98$ (2019)

10. M. Major, J. Kalinowski, M. Kosiń, Thin-walled C-profile for use during light steel construction, has left element and right element whose opposite sides are fixed corresponding to inner shape of thin-walled profile, and internal base selected after folding three elements, 2017, PL423102 - patent

11. M. Major, I. Major, M. Kosiń, Transactions of the VSB - Technical University of Ostrava. Civil Engineering Series, 17 (2017)

12. M. Major, I. Major, J. Kalinowski, M. Kosiń, Transactions of the VSB - Technical University of Ostrava. Civil Engineering Series, 18 (2018).

13. H.-H. Lee, Finite Element Simulations with Ansys Workbench 13 (Schroft Development Corporation 2011)

14. Ansys-Workbench v. 18.1 system documentation. 